saved by this very simple procedure. But the use of the term "puerperal fever" seems to produce a feeling of mystery and of dread in regard to the poor sufferers, insomuch that medical men as well as midwives avoid close contact or even any connexion with a puerperal case. The disease is looked upon in the same way that scarlet fever and erysipelas are looked upon, and the only desire is to get rid of the patient as soon as possible. When asepsis fails in an operation wound the surgeon does not act in this manner. He opens up the wound, drains it, or washes it out with an antiseptic, taking care, by the use of gloves, antiseptics, \&c., that his hands and dress are not polluted through his attention to such a case. The same course could, and should, be carried out in obstetrics. But it must be carried out by medical men, not by midwives. It seems to me that all the midwives of a district should be under the supervision of a medical man whose attention should be called to all cases of pyrexia in the lying-in period and to whom all confinements in his district should be reported each morning as they take place and for whose well-being he would be considered responsible. He should be well remunerated for his services and it should be understood that his duty was to ascertain and to remove all preventable causes of puerperal mortality. He would guide and encourage midwives in their efforts to carry out aseptic midwifery. At present punishment by suspension is what the midwife has to fear, but this only occurs in flagrant cases, especially where death has occurred, and is a poor satisfaction to mourning relatives, and may be hard on the midwife who perhaps tried to obtain the help of a medical man but could not. The Midwives Act is defective in that it does not afford to the poor honest women of the country anything like as complete facilities in their confinements as those which the Poor-law affords to the pauper mothers who are confined under its patronage.

Liverpool.

\section{A CASE OF MULTIPLE CIRCUMSCRIBED LIPOMATA TREATED WITH ETHYLATE OF SODIUM.}

BY AGNES F. SAVILL, M.A. ST. AND., M.D. GLASG., M.R.C.P. IREL.

AESISTANT PHYSTCIAN TO ST. JOHN'S FOSPITAL FOR DISEASES OF THE SKIN, LEICESTER-BQUARE.

THE following case of multiple circumscribed lipomata is of interest owing to the remarkable improvement under treatment.

The patient, a male, aged 31 years, came under my care at the hospital in June, 1903, complaining of "swellings under the skin" with considerable itching over some of them.

History of the "snellings." -In 1895, when the patient was 24 years old, he noticed a swelling somewhat smaller than a cherry on the flexor aspect of the right forearm. It itched a good deal, and as it slowly increased in size he went to Guy's Hospital, where it was excised. About a year later a second swelling appeared on the flexor aspect of the left forearro. So far as the patient can tell, no other swelling became visible till 1900 (i.e., nearly four years later). Between 1900 and 1903 they rapidly increased in number on the arms, legs, and trunk, and the larger ones caused itching.

Condition of swellings in June, 1903.-The swellings numbered between 17 and 20 ; the precise number was unfortunately not noted at the time because it was not expected that they would soon respond to treatment. The swellings were only roughly symmetrical in position and were situated immediately beneath the skin. Most of them were freely moveable and could be picked up between the finger and thumb; the older and larger ones appeared to have prolongations downwards into the muscular tissue. They varied in size from a threepenny-piece to a five-shillingpiece in diameter; the skin above them was raised about half an inch to an inch above the surrounding skin. The largest was not quite as large as an ordinary hen's egg and the smallest felt like a pea; many were flattened like an almond. The larger swellings had one or two pea-sized satellites in their vicinity. The swellings were hard and the skin above them showed no puckering when pinched up; they had a definite circumscribed outline and were not lobulated. The skin over the older tumours was pink, with dilated venules visible to the naked eye. The tumour which had appeared in 1896 was very firm and of about the size of an almond; it was excised and examined microscopically, and proved to be of typical lipomatous structure.

Family history.-The patient had five brothers and four sisters. Two of the sisters died young; one is mentally deficient. One brother, aged 25 years, developed a "swelling " in 1905, but I have not seen him.

Q eneral health.-The patient had measles in childhood. In 1896 he had scarlet fever. He never had rheumatic fever. There was no history of syphilis, but he had a soft chancre in 1895. He was of average height, with a short neck and broad chest. There was no obesity. The heart and lungs appeared to be normal; the liver edge was just palpable on deep inspiration. The patient regarded himself as enjoying average health but there were about him signs of defective vascular tone, unmistakeable to an experienced eye. The skin showed irregular mottling over almost the whole of the body. This mottling is visible in many individuals with defective circulation during cold weather but this patient showed the condition even on a warm day. All along the costal margin of the thorax there were telangiectases. The facial contour varied from day to day, having a flabby appearance when the patient felt "slack," and at such times the orbital fissure became narrowed, although no definite cdema beneath the eyes was ever seen. Every physician recognises this marked variation of the facial contour in subjects of what, for want of knowledge of the cause, we term deficient vascular tone. The extremities were frequently blue and swollen; the finger ends were inclined to be bulbous. The patient said that after a heavy meal, especially on a cold day, his ears and fingers up to the knuckles often became white and numb. He had been accustomed to take from three to six glasses of beer daily since the age of 20 . He took spirits at times but had never been a hard drinker.

Treatment.-1. Local treatment consisted in painting the skin over each swelling with ethylate of sodium. At first this was done once a week but after a month the patient in his zeal exceeded his instructions and began to paint the skin daily. This set up inflammation and he developed a superficial ulcer over the largest lipoma, situated just above the right buttock, and redness and tenderness over several others. This was readily soothed down and the patient was instructed to paint the swellings two or three times weekly till the skin should become reddened, then to leave off local treatment until the skin returned to its normal condition, when the application might again be resumed. These direc. tions were faithfully carried out until the early spring of 1906. He was then ordered to massage and rub the remaining lipomata and to douche them with as hot water as he could tolerate. 2 . The general treatment was perhaps as important as the local treatment. A teetotal regimen was prescribed. At first the diet was regulated in order to improve the dyspepsia but after a few months no restrictions were placed upon the diet. Active exercise in the form of bicycling had always been a favourite pastime with the patient and he was encouraged to continue the habit more regularly. In the spring of 1904 he began to practise deep breathing exercises and Swedish movements and has gradually increased these, practising them morning and evening. The constipation has been treated on the usual lines of diet, exercise, and pills of aloin with nux vomica. Various tonics containing strychnine or nux vomica, quinine, phosphoric acid, and iron were given at intervals from 1903 to 1906. In May and June, 1904, thyroid ( $2 \frac{1}{2}$ grains three times a day) was tried but had to be omitted because of the " clammy hot attacks" he suffered from whenever he took it regularly. In March, 1906, he was put on 20-grain doses of calcium chloride three times a day with the object of reducing the blueness and swelling of the fingers during the cold spring winds. He continued to take this from time to time till the warm weather of summer; it did not affect the remaining lipomata but it improved his general health and made him feel " braced up."

Effects of treatment. - No fresh tumour appeared after the commencement of treatment although between 16 and 19 lipomata had appeared within the three preceding years. A marked diminution in the size of the softer lipomata was noticed within a few months from the beginning of treatment, and by November, 1904-i.e., in less than 18 months-only 12 lipomata could be found, the smallest tumours having entirely disappeared. The remaining dozen very slowly but very steadily decreased in size. To-day (March, 1907) 
on looking at the surface of the body of the patient there is only one slight swelling visible to the eye over a lipoma which is situated on the extensor aspect of the right thigh. It is only after most careful palpation that ten swellings can be discovered in the sites where, three years previously, there existed prominent tumours. Four of these remaining lipomata give to the examining finger a sensation as of a flat bean situated in the muscular tissue (being impalpable except on picking up the muscular tissue); six are not larger than a pea and are equally deeply situated and difficult to palpate. Several fine cicatricial areas are present over them, the result of the over-zealous preliminary treatment. The general health is much improved; the skin is less mottled, the eyes are bright, the lethargy and dyspepsia have vanished, and the movements are more alert. The telangiectases along the costal margin are still present but have not increased.

Previously recorded cases. - The literature on this subject is more scanty than would be expected. Surprised at the good result of treatment in my case I looked up the bibliography of multiple lipomata and found it consisted largely of short descriptions of cases of diffuse lipomata, the majority of whom had been exhibited at the medical societies. There was little reference to treatment. Previous to the introduction of antiseptics there are several interesting records of treatment in the French medical journals. The writers point out the usefulness of their methods of treatment, by which "all bleeding is avoided, and above all, erysipelas, which sometimes leads to death." After antiseptics rendered excision free from danger, there is but little further record of other than surgical treatment for lipomata. In 1839 Leviez $^{1}$ mentioned a case of a large fatty tumour under the chin which resisted all liniments, but after pustulation had been induced by friction with a certain pomade a cure ensued. In 1859 Legrand" described a method of linear cauterisation by zinc chloride, followed by application of caustics to the exposed tumour. He admits the painfulness of the procedure, but praises its safety. In $1863 \mathrm{Dr}$. Saul ${ }^{3}$ reported a case of multiple tumours which improved slightly under potassium iodide in doses of six grains three times a day. The tumours appeared to be of a lipomatous nature, but no microscopical examination was made. In $1872 \mathrm{Mr}$. J. Gay ${ }^{4}$ described a case of multiple lipomata which resembled my case more than any other description I have met with. The tumours were firm and hard, with well-defined outline, situated immediately beneath the epiảermis. They occurred in a stout middle-aged man who suffered from dyspepsia and cold extremities. Under a course of treatment directed to the improvement of the general health and frequent hot baths $\left(120^{\circ}\right.$ to $130^{\circ} \mathrm{F}$.), given with the aim of liquefying the fat and so promoting its absorption, many of the tumours disappeared and the hard ones became softened. In 1881 Dr. Pritchard ${ }^{5}$ reported a case of multiple symmetrical lipomata, averaging in size a small bean. They had lasted for 25 years ; some disappeared when fat in other parts of the body decreased. In 1887 Dr. W. K. Sibley ${ }^{6}$ exhibited a case of a man, aged 32 years, who for five years had symmetrical lipomata appearing on the body. $\mathrm{He}$ was a plethoric individual whose face showed capillary dilatation; and he was addicted to drinking beer and spirits. When he was working hard the swellings became reduced in size. In 1886 Mr. Morrant Baker and Mr. A. A. Bowlby ${ }^{7}$ described a large number of cases with multiple diffuse lipomata in which the individual swellings were from five to six inches long, softer and more deeply situated than in Mr. Gay's case, and of indefinite outline. They referred at the same time to previously recorded cases and drew attention to the fact that the patients were males and that in almost every case there was a history of hard drinking of beer and spirits. A few cases had derived slight benefit from the administration of liquor potassæ 20 minims three times a day (Brodie's ${ }^{8}$ method). No good had resulted in cases treated with tincture of iodine internally. In Quain's "Dictionary of Medicine" (third edition) the following interesting remarks occur in the

\section{Gazette Médicale de Paris, 1839.}

2 Gazette des Hôpitaux, 1859 .

3 Transactions of the Pathological Society of London, vol. xv.

4 THE 5 ANCET, Oct. 26th, 1872 , p. 593

6 Transactions of the Pathological Society of London, vol. xxxix. 7 Transactions of the Royal Medical and Chirurgical Society, 1885, vol. Ixix.

8 Brodie: Lectures on Pathology and Surgery, 1846, p. 202 (American edition). paragraph dealing with the treatment of lipomata: "Thongh fatty tumours are said to shift their position, and sometimes to diminish in size spontaneously, they are not to be dispersed by internal remedies or external applications. ...... It is said that if they result from beer-drinking they will diminish if the habit be discontinued."

Remarks.-The case is of interest both from the pathological and the therapeutical point of view. The pathological interest lies in the association of fatty deposits and telangiectases and the possible relationship between these two phenomena. As the patient was unaware of the thoracic telangiectases and mottling of the skin it is impossible to say whether they preceded or followed the lipomata. The long history of white and numb fingers and ears points to the presence of a defective circulation existing for many years. In such subjects beer and spirits, being vascular dilators, are very injurious and tend to increase the unhealthy condition of the peripheral circulation. It has long been recognised that obesity is associated with defective circulation and it has been considered that the phenomenon is due to the resulting defective oxygenation of the tissues. Thus, obesity occurs with anæmia and with cardiac disease in certain persons. It is quite probable that the local fat deposits in the above case were due to a local stagnation of the circulation. Obesity in certain regions has been reduced by massage and irritants applied to the overlying skin, the reduction probably being due to the increased blood-supply to the part. It was with this idea in mind thit I commenced treatment with a strong caustic application over the tumours. As I did not expect the result which has fortunately occurred, the notes of the precise measurements, sites, and rapidity of diminution of the lipomata are not so accurate as they would otherwise have been. The treatment was pushed in the early stage till a dermatitis was excited; and the diminution of the tumours was very rapid during the first tiwo months, more rapid than during the later stages, when dermatitis was avoided. In the spring of 1906 the patient observed that the lipomata had not made much improvement during the previous half year; and therefore the caustic applications were discontinued. The remaining portions of the lipomata (with the one exception above referred to) were at that time so deeply situated that it was improbable that cutaneous applications could affect them.

This method of treatment by caustics may be recommended where operation is inadmissible, by reason of the large number of the tumours, objection on the part of the patient, or for any other cause. In cases where it is desirable to avoid the scarring consequent on excision, this method may also be recommended because if carefully performed under medical supervision no scar need result.

Upper Berkeley-street, w.

\section{THE TEACHING OF THE HYGIENE THE EXPECTANT AND SUCKLING MOTHER. ${ }^{1}$}

BY JOHN F. J. SYKES, M.D., D.Sc. EDIN., MEDICAL OFFIOER OF HEALTH OF ST. PANCRAS.

[Dr. Sykes commenced his paper by saying that in times past various factors had been assigned as the causes of a high infantile mortality. It now, however, seemed clear that faulty maternal hygiene was the fons et origo mali. The resisting powers of the infant by which it is enabled to fight adverse influences should be acquired and maintained for the nine months before birth just as much as during the nine months after birth. Therefore the hygiene of the expectant mother takes first rank and this, with the hygiene of the suckling mother, precedes all other considerations. Dr. Sykes then quoted certain statistics as to decrease in birth-rate increase in the mortality of infants under one year, and decrease of breast-feeding. He continued :- ]

Infantile mortality, from the point of view of deficient nutrition and viability, may be expressed in the following form :-

A. Ante-partum and ante-natal causes.-(a) As to the mother, resulting in (1) diminished vigour and reduced resistance to adverse influences; or (2) deficient nutrition, growth, and differential development of the embryo. (b)

1 Abstract of a paper read on June 13th, 1906. 